\title{
PENINGKATAN PENGETAHUAN TENTANG SEJARAH BAGI SISWA-SISWI SMP NEGERI 2 KELAPA DUA TANGERANG MELALUI WISATA EDUKASI
}

\author{
Yustisia Kristiana ${ }^{1}$
}

\begin{abstract}
Edutourim is a program that combines elements of tourist activities with education. Edutourim is expected to be a means to preserve the culture values and introduce the history and culture of Indonesia. This is because the phenomena in the younger generation who are no longer interested in studying history. Sekolah Tinggi Pariwisata Pelita Harapan, Universitas Pelita Harapan develop educational travel programs that cater for students of junior high schools to develop interest in learning history. Students of SMP Negeri 2 Kelapa Dua, Tangerang selected to attend this edutourism program by visiting Monumen Nasional and Museum Sejarah Jakarta. This program was conducted on Tuesday, April $17^{\text {th }}, 2012$ with total participants were 20 students and two teachers. Edutourism program led by lecturer and guided by students of Travel Industry Management. The students and the team from Travel Industry Management were very enthusiastic during the edutourism. Benefits derived by the students through these program are (1) to increase the understanding about historical sites in Jakarta; (2) to increase the knowledeg about historical sites in Jakarta; and (3) to develop the partnership between the SMP Negeri 2 Kelapa Dua, Tangerang and Sekolah Tinggi Pariwisata Pelita Harapan, Universitas Pelita Harapan. The edutourism program is well accepted and effective to increase student's interest in learning history.
\end{abstract}

Key words: edutourism, student's interest in learning history, historical site

\section{PENDAHULUAN}

Wisata adalah kegiatan perjalanan yang dilakukan oleh seseorang atau sekelompok orang dengan mengunjungi tempat tertentu untuk tujuan rekreasi, pengembangan pribadi atau mempelajari keunikan daya tarik wisata yang dikunjungi dalam jangka waktu sementara. Defini ini tertuang dalam UndangUndang No. 10 Tahun 2009 Tentang Kepariwisataan. Terdapat beragam jenis wisata diantaranya adalah wisata minat khusus. Menurut Read (1980) dalam Hall dan Weiler (1992) wisata minat khusus merupakan perjalanan wisata yang diperuntukkan bagi wisatawan tertentu yang memiliki tujuan yang berbeda. Salah satu contoh dari wisata minat khusus adalah wisata edukasi. Wisata edukasi

\footnotetext{
${ }^{1}$ Jurusan Manajemen Usaha Wisata, STPPH, Universitas Pelita Harapan, yustisia.kristiana@uph.edu
} 
merupakan suatu program yang menggabungkan unsur kegiatan wisata dengan muatan pendidikan didalamnya.

Wisata edukasi sangat diharapkan menjadi sarana untuk melestarikan budaya dan mengenalkan nilai luhur sejarah dan budaya bangsa Indonesia. Hal ini dikarenakan adanya fenomena di generasi muda yang tidak lagi tertarik mempelajari sejarah. Kartodirdjo (1995) meyakini bahwa persepsi tentang sejarah di kalangan pelajar sangatlah kurang bahkan sering tidak ada sama sekali dan minat terhadap sejarah juga sangat minim. Suryo (1991) mengungkapkan bahwa (1) terdapat kemerosotan pengetahuan, kesadaran dan pengajaran tentang sejarah, (2) pengajaran sejarah dinilai tidak menarik dan cenderung membosankan, dan (3) menurunnya semangat kebangsaan dan patriotisme di kalangan generasi muda. Bila tidak dilakukan perubahan maka dapat dipastikan generasi muda tidak lagi mengenal sejarah bangsanya. Sejarahlah yang mampu mengungkapkan asal mula dan perkembangan, baik itu warisan dari leluhur, nilai-nilai, adat istiadat, lembaga-lembaga, teknologi, sistem dan lain sebagainya. Sejarah menjadi sumber inspirasi dan aspirasi generasi muda (Kartodirdjo, 1995).

Berdasarkan latar belakang tersebut, Sekolah Tinggi Pariwisata Pelita Harapan, Universitas Pelita Harapan mengembangkan program wisata edukasi yang diperuntukkan bagi siswa-siswi sekolah menengah pertama untuk meningkatkan pengetahun siswa tentang sejarah. Siswa-siswi dari SMP Negeri 2 Kelapa Dua, Kabupaten Tangerang dipilih untuk mengikuti program wisata edukasi. SMP Negeri 2 Kelapa Dua, Kabupaten Tangerang terletak kira-kira 2 km dari kampus Universitas Pelita Harapan dan sekolah ini tidak memiliki program karyawisata. Jakarta dipilih sebagai destinasi dari penyelenggaraan wisata edukasi. Jakarta memiliki banyak obyek wisata yang dapat dimanfaatkan untuk belajar tentang sejarah, diantaranya adalah Museum Sejarah Jakarta dan Monumen Nasional. Museum Sejarah Jakarta merupakan salah satu museum yang memiliki nilai historis perjalanan sejarah kota Jakarta sebagai pusat ibu kota negara Indonesia. Sedangkan Monumen Nasional adalah lambang negara Indonesia, yang pembangunannya dipelopori oleh Presiden Republik Indonesia yang pertama yaitu Ir. Soekarno. Monumen Nasional merupakan tugu kebanggaan bansga Indonesia. Sekolah Tinggi Pariwisata Pelita Harapan (STPPH) melihat bahwa siswa-siswi SMP Negeri 2 Kelapa Dua, Tangerang perlu diberikan edukasi mendalam tentang kedua tempat tersebut yaitu Monumen Nasional dan Museum Sejarah Jakarta. Oleh karena itu, diselenggarakan perjalanan wisata sambil belajar di kedua obyek wisata tersebut sebagai bentuk pengabdian kepada masyarakat.

\section{METODE PEMECAHAN MASALAH}

Wisata edukasi ini dilakukan dengan metode karyawisata yaitu dengan cara mengunjungi obyek wisata sejarah di Jakarta. Adapun tahap pelaksanaannya dimulai dengan persiapan. Dalam tahap persiapan ini kegiatan yang pertama dilakukan adalah pengajuan proposal. Setelah proposal disetujui, tim menghubungi Kepala Sekolah SMP Negeri 2 Kelapa Dua, Tangerang untuk kepastian tanggal pelaksanaan dan pengaturan jumlah siswa yang akan mengikuti wisata edukasi serta persiapan teknis lainnya. Tim juga melaksanakan survei obyek wisata, mempersiapkan pertanyaan untuk evaluasi kegiatan, menentukan 
hipotesa serta menyiapkan materi memandu bagi peserta wisata edukasi. Hipotesa yang dikemukakan adalah:

Ho. Wisata edukasi tidak memberikan peningkatan pengetahuan siswa tentang sejarah khususnya Museum Sejarah Jakarta dan Monumen Nasional

Ha. Wisata edukasi memberikan peningkatan pengetahuan siswa tentang sejarah khususnya Museum Sejarah Jakarta dan Monumen Nasional

Pelaksanaan wisata edukasi dimulai pada pukul 07.00 sampai dengan pukul 16.00. Obyek wisata yang dikunjungi adalah Museum Sejarah Jakarta dan Monumen Nasional. Tim pelaksana terbagi tugas sebagai tour leader, pemandu wisata, seksi konsumsi, seksi dokumentasi dan seksi perlengkapan. Siswa diantar jemput dari sekolah menuju obyek wisata di Jakarta dan kembali ke sekolah. Kegiatan ini juga dilakukan proses evaluasi. Evaluasi kegiatan meliputi pemberian pre test kepada siswa tentang Museum Sejarah Jakarta dan Monumen Nasional. Setelah mengikuti kegiatan wisata edukasi, siswa diberikan post test. Sebagai indikator keberhasilan kegiatan ini adalah adanya peningkatan pengetahuan siswa tentang Museum Sejarah Jakarta dan Monumen Nasional. Peningkatan ini dapat dilihat dari hasil analisis data skor siswa pada pre test dan post test. Teknik analisis data yang dipergunakan berupa analisis deskriptif kualitatif terhadap data yang diperoleh dari hasil observasi, sedangkan analisis data kuantitatf terhadap data hasil pre test dan post test, menggunakan analisis statistika paired sample $t$ test. Kriteria pengujian yang digunakan adalah (Santoso dan Ashari, 2005):

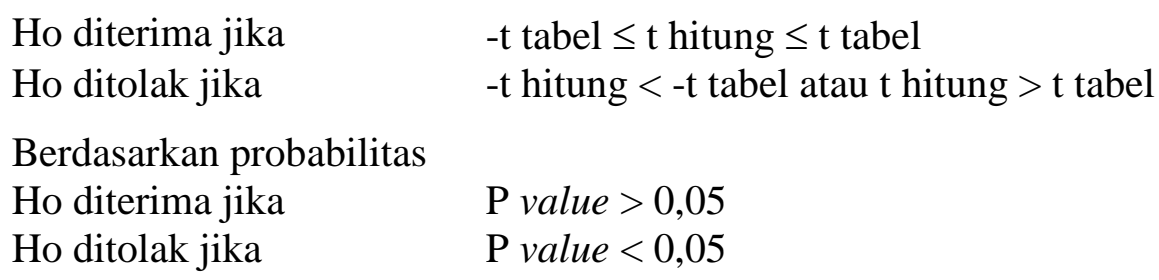

\section{HASIL DAN PEMBAHASAN}

Wisata edukasi ini diikuti oleh 20 orang siswa SMP dan dilaksanakan pada hari Selasa, 17 April 2012. Para peserta wisata edukasi terlihat sangat antusias dalam mengikuti kegiatan. Hal ini terlihat dari banyaknya siswa yang mengajukan pertanyaan pada saat mahasiswa STPPH yang bertugas sebagai pemandu wisata menyampaikan informasi.

Gambar 1. Kegiatan Wisata Edukasi 

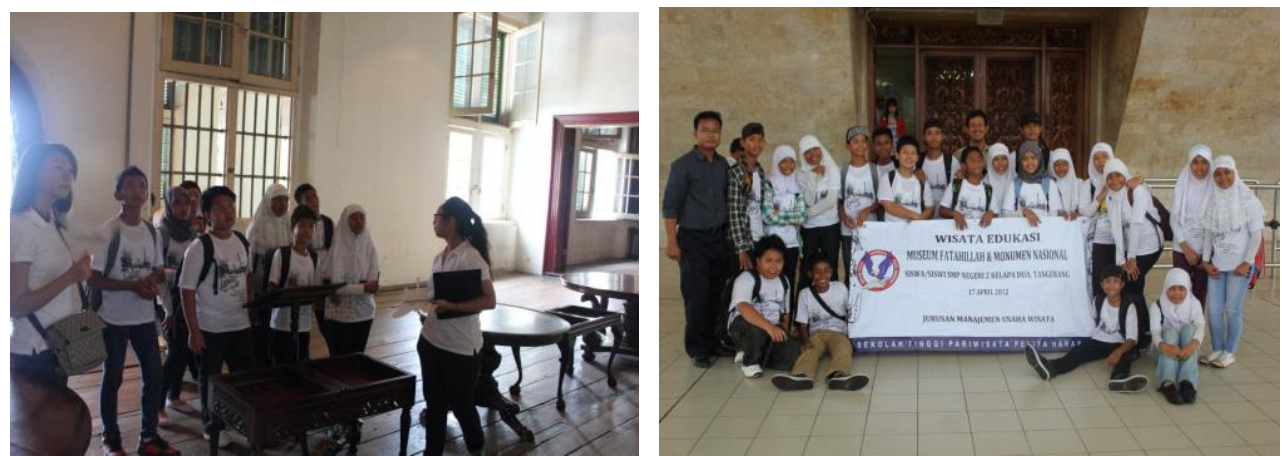

Skor jawaban siswa terhadap pertanyaan mengenai Museum Sejarah Jakarta dan Monumen Nasional dikelompokkan dalam empat kategori yaitu kurang, cukup, baik dan sangat baik. Kategori kurang berada pada interval $0-5,5$, kategori cukup berada pada interval 5,6 - 7,5 dan kategori baik berada pada interval 7,6 10. Tabel 1 menunjukkan hasil pre test yang dilakukan.

Tabel 1. Hasil Pre Test

\begin{tabular}{lrr}
\hline \multirow{2}{*}{ Kategori } & \multicolumn{3}{c}{ Jumlah } \\
\cline { 2 - 3 } & N & \% \\
\hline Kurang & 14 & 70 \\
Cukup & 5 & 25 \\
Baik & 1 & 5 \\
\hline Total & 20 & 100 \\
\hline
\end{tabular}

Sumber: Hasil data olahan (2012)

Tabel di atas memperlihatkan bahwa dari 20 siswa peserta wisata edukasi terdapat 14 orang $(70 \%)$ dalam kategori kurang, 5 orang $(25 \%)$ dalam kategori cukup dan 1 orang (5\%) dalam kategori baik. Pada akhir kegiatan, siswa diberikan post test untuk mengetahui apakah informasi yang diberikan melalui kegiatan wisata edukasi dapat meningkatkan pengetahuan siswa tentang sejarah terutama tentang Museum Sejarah Jakarta dan Monumen Nasional. Hasilnya dapat dilihat pada Tabel 2.

Tabel 2. Hasil Post Test

\begin{tabular}{lrr}
\hline \multirow{2}{*}{ Kategori } & \multicolumn{3}{c}{ Jumlah } \\
\cline { 2 - 3 } & $\mathbf{N}$ & $\%$ \\
\hline Kurang & 0 & 0 \\
Cukup & 4 & 20 \\
Baik & 16 & 80 \\
\hline Total & 20 & 100 \\
\hline
\end{tabular}

Sumber: Hasil data olahan (2012)

Hasil post test menunjukkan bahwa terdapat pengurangan jumlah siswa yang berada dalam kategori kurang dan cukup, serta terjadi peningkatan terhadap jumlah siswa yang berada dalam kategori baik dan sangat baik. Tabulasi silang yang dilakukan antara hasil pre test dan post test dapat dilihat pada Tabel 3.

Tabel 3. Tabulasi Silang Antara Hasil Pre Test Dan Post Test

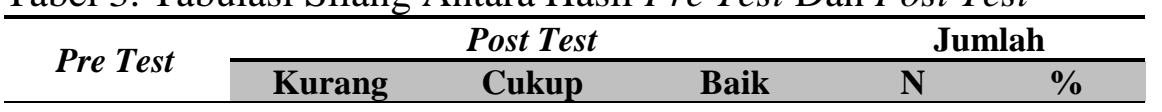




\begin{tabular}{llrrrr}
\hline Kurang & 0 & 4 & 10 & 14 & 70 \\
Cukup & 0 & 0 & 5 & 5 & 25 \\
Baik & 0 & 0 & 1 & 1 & 5 \\
\hline N & 0 & 4 & 16 & 20 & \\
\hline \% & 0 & 20 & 80 & & \\
\hline
\end{tabular}

Sumber: Hasil data olahan (2012)

Tabel 3 memperlihatkan bahwa 14 siswa yang awalnya berada dalam kategori kurang, terdapat 4 orang yang meningkat menjadi kategori cukup, dan 10 orang meningkat menjadi kategori baik pada hasil post test. Demikian juga dari 5 orang yang hasil pre test dalam kategori cukup meningkat menjadi kategori baik. Sedangkan 1 orang yang berada dalam kategori baik pada hasil pre tetap dalam kategori baik pada hasil post test. Hal ini menunjukkan bahwa kegiatan wisata edukasi dapat meningkatkan pengetahuan sejarah dari siswa, terutama yang berkaitan dengan Museum Sejarah Jakarta dan Monumen Nasional.

Analisis data kuantitatif terhadap data hasil pre test dan post test menggunakan uji t. Hasilnya dilihat pada Tabel 4.

Tabel 4. Hasil Uji t

\begin{tabular}{|ll|r|r|r|r|}
\hline & \multicolumn{1}{|l|}{ Mean } & \multicolumn{1}{l|}{ N } & Std. Deviation & \multicolumn{1}{l|}{ Std. Error Mean } \\
\hline Pair 1 & Pre Test & 5,05 & 20 & 1,356 & 0,303 \\
& Post Test & 8,20 & 20 & 1,105 & 0,247 \\
\hline
\end{tabular}

\begin{tabular}{|lc|c|r|r|}
\hline & $\mathrm{N}$ & Correlation & \multicolumn{2}{c|}{ Sig. } \\
\hline Pair 1 & Pre Test \& Post Test & 20 & 0,871 & 0,000 \\
\hline
\end{tabular}

\begin{tabular}{|c|c|c|c|}
\hline & & & $\begin{array}{c}\text { Pair } 1 \\
\text { Pre Test-Post Test }\end{array}$ \\
\hline $\begin{array}{l}\text { Paired Differences } \\
t_{t} \\
d f \\
\text { Sig. (2-tailed) }\end{array}$ & $\begin{array}{l}\text { Mean } \\
\text { Std. Deviation } \\
\text { Std Error Mean } \\
95 \% \text { Confidence Interval of } \\
\text { the Difference }\end{array}$ & $\begin{array}{l}\text { Lower } \\
\text { Upper }\end{array}$ & $\begin{array}{r}-3,150 \\
0,671 \\
0,150 \\
-3,464 \\
-2,836 \\
-21,000 \\
19 \\
0,000\end{array}$ \\
\hline
\end{tabular}

Sumber: Hasil output SPSS (2012)

Tabel 4 menunjukkan rata-rata skor siswa sebelum diberikan informasi (pre test) adalah 5,05 dan rata-rata skor siswa setelah mengikuti kegiatan wisata edukasi (post test) adalah 8,20. Nilai korelasi antara skor pre test dengan post test adalah sebesar 0,871 dengan probabilitas 0,000 (di bawah 0,05). Hal ini menunjukkan terdapat korelasi positif antara skor sebelum dan setelah kegiatan wisata edukasi. Sedangkan hasil uji $\mathrm{t}$ diperoleh nilai t hitung sebesar $-21,000$ dengan probabilitas 0,000. Nilai t hitung $-21,000<-2,093$ ( t tabel) dan probabilitas $0,000<0,05$ maka Ho ditolak. Hal ini menunjukkan bahwa wisata edukasi memberikan peningkatan pengetahuan siswa tentang sejarah, khususnya Museum Sejarah Jakarta dan Monumen Nasional.

\section{SIMPULAN DAN SARAN}




\section{Simpulan}

Hasil analisis skor pre test dan post test untuk 20 orang siswa yang mengikuti kegiatan wisata edukasi, nilai rata-rata pre test adalah 5,05 dan nlai rata-rata post test adalah sebesar 8,15 . Hal ini menunjukkan bahwa kegiatan belajar sejarah dalam bentuk wisata edukasi ini dapat meningkatkan pengetahuan siswa hingga 61,39\%. Hasil uji t diperoleh nilai t hitung -19,304 <-2,093 (t tabel) dan probabilitas $0,000<0,05$ maka Ho ditolak. Hal ini menunjukkan bahwa wisata edukasi memberikan peningkatan pengetahuan siswa tentang sejarah khususnya Museum Sejarah Jakarta dan Monumen Nasional.

Saran

Perlu dikembangkan sistem pengajaran yang menarik dalam penyampaian sejarah bagi siswa-siswi SMP Negeri 2 Kelapa Dua, Tangerang. Hal ini terlihat pada hasil pre test yang menunjukkan bahwa sebesar $70 \%$ dari siswa tidak dapat menjawab pertanyaan yang diberikan. Kegiatan karyawisata dapat dijadikan kegiatan rutin sebagai sarana untuk meningkatkan pengetahuan, bukan hanya tentang sejarah tetapi juga ilmu pengetahuan lainnya.

\section{UCAPAN TERIMA KASIH}

Kegiatan wisata edukasi ini dapat terlaksana dengan baik berkat adanya dukungan dari semua pihak. Ucapan terima kasih disampaikan kepada Ketua Sekolah Tinggi Pariwisata Pelita Harapan, Ketua Jurusan Manajemen Usaha Wisata, Kepala Sekolah SMP Negeri 2 Kelapa Dua, Tangerang, mahasiswa jurusan Manajemen Usaha Wisata angkatan 2010 dan siswa-siswi SMP Negeri 2 Kelapa Dua, Tangerang.

\section{DAFTAR PUSTAKA}

Hall, C. M. dan Weiler, B. (1992). Special interest tourism. London: Bellhaven Press.

Kartodirdjo, Sartono (1995). Perkembangan penulisan sejarah Di Indonesia selama setengah abad, Makalah. Semarang: Universitas Diponegoro

Read, S. E. (1980). A prime force in the expansion of tourism in the next decade: special interest tourism. In Hawkins, D. E.; Shafer, E. L.; Rovelsatd, J. M. (Eds.). Tourism marketing and management issues. Washington DC: George Washington University.

Santoso, Budi P. dan Ashari (2005). Analisis statistik dengan Microsoft Excel dan SPSS. Yogyakarta: Andi Offset.

Suryo, Djoko (1991). Pengajaran sejarah dan globalisasi kehidupan, Makalah Pada Seminar Pengajaran Sejarah dan Perubahan Sosial. Surakarta: Unversitas Negeri Sebelas Maret.

Undang-Undang Republik Indonesia 2009, No. 10 Tahun 2009 Tentang Kepariwisataan (2009). 